\title{
Expression of HMGR in Lilu cattle tissues
}

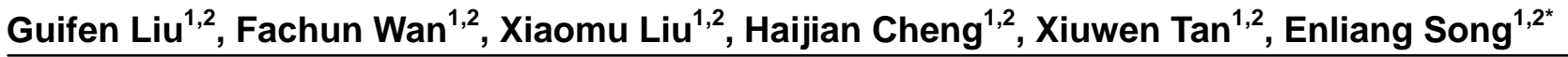 \\ ${ }^{1}$ Institute of Animal Science and Veterinary Medicine, Shandong Academy of Agricultural Sciences, Jinan, China \\ ${ }^{2}$ Shandong Key Lab of Animal Disease Control and Breeding, Jinan, China; ${ }^{*}$ Corresponding Author: eliangs@126.com \\ Received 21 September 2011; revised 28 November 2011; accepted 8 December 2011
}

\begin{abstract}
The 3-hydroxy-3-methylglutaryl-CoA reductase $(H M G R)$ is an essential enzyme in cholesterol biosynthesis. To study the expression of HMGR in adipose and muscle tissues, and some performance indexes of four age stages, twelve Lilu cattle were selected. The results indicated that the Lilu beef cattle have good production and slaughter performance. HMGR mRNA expression level in adipose was higher than in muscle, but the trend in adipose was the same as in muscle. HMGR mRNA expression is difference in adipose and muscle tissues suggesting this gene is expressed in a tissue-dependent manner in cattle. Understanding the causes of variation in $H M G R$ gene expression may provide crucial information about cholesterol biosynthesis in Lilu beef cattle.
\end{abstract}

Keywords: 3-Hydroxy-3-methylglutaryl-CoA Reductase; mRNA Expression; Tissues; Cattle

\section{INTRODUCTION}

Cholesterol is a fat-like substance in the body. Despite cholesterol's bad reputation, the body needs cholesterol to maintain cell membrane functionality, synthesis of steroid hormones and production of bile acids, which aid in fat absorption in the intestines. Moreover, cholesterol is a major component of the myelin sheaths and therefore is essential for optimal neuronal health [1]. As a result, the body needs cholesterol, which can be derived form dietary sources or synthesized by the liver. Precise control of plasma cholesterol levels is critical because excessive cholesterol is known to predispose to the development of atherosclerosis and cardiovascular disease [2].

Three-hydroxy-3-methylglutaryl-CoA reductase (HMGR) catalyzes the conversion of HMG-CoA to mevalonate and is considered the rate-limiting enzyme in the overall pathway of cholesterol biosynthesis [3]. Somebody found that lipogenic activity in chicken and human liver is much greater than that in adipose tissue, whereas in rat and swine, adipose tissue is the major site of cholesterol synthesis [4].

Lilu beef cattle is breeded through the method of crossing fixed and combined with directional excellentchoosing individual which include $62.5 \%$ introduced Limousin blood and 37.5\% local Luxi cattle blood. Hybrid offspring have good production performance and adaptability. Now, these breeds are the stage of new varieties approved. The objective of the present study was to evaluate the production performance, slaughter performance and effects of tissue on $H M G R$ expression in four age stages of Lilu beef cattle.

\section{MATERIALS AND METHODS}

\subsection{Animal Housing and Tissue Sampling}

In the present study, at each of $12,18,24$, and 30 months of age, $3 \mathrm{Li}$-Lu beef cattle were provided. The animals were reared and sacrificed in compliance with national regulations for the humane care and use of animals in research. The longissimus dorsi muscle near the last thirteenth or fourteenth rib was rapidly and manually dissected from each cleaved cattle. These samples were immediately submerged in liquid nitrogen until further use.

\subsection{The Measurement of Fleshcolor and Sheer Force of Lilu Beef Cattle}

The mimulta chroma meter was selected to detect the fleshcolor, the $\mathrm{L}, \mathrm{a}, \mathrm{b}$ value were measured respectively. The digital tenderness meter of Model C-LM3B is used for the measurement of the meat tenderness of muscle [5]. The muscle was taken out when the center of muscle is reach to $70^{\circ} \mathrm{C}$. Parallel direction with the muscle fiber to drill muscle with a round sampler muscle, $1.27 \mathrm{~cm}$ little meat column were taken, each muscle take 10 to 12 meat column. The meat column was sheared in tenderness meter, and records the data. The average of 6 values serve as the shear force of this muscle.

\subsection{RNA Extraction}

Total RNA was isolated from muscle using Trizol re- 
agent (Invitrogen, Carlsbad, CA, USA). All the procedures were based on the manufacturer's protocol. The concentration of RNA was determined using spectrophotometry based on absorbance at $260 \mathrm{~nm}$ and integrity was monitored using Agilent 2100 Bioanalyzer (Agilent Technology, USA), QC Criteria: RIN $>=7.0$ and 28S/ $18 \mathrm{~S}>0.7$.

\subsection{RT-PCR}

To analyze gene expression pattern of the HMGR gene in adipose and muscle. The $\beta$-actin was used as the housekeeping gene. Real-time qRT-PCR were performed using the ABI Prism 7700 Sequence Detector (Applied Biosystems, Foster City, CA, USA) in a final volume of $20 \mu \mathrm{L}$ containing SYBR Green I (Invitrogen). Cycling conditions were as follows: $94^{\circ} \mathrm{C}$ for $2 \mathrm{~min}, 35$ cycles of $94^{\circ} \mathrm{C}$ for $30 \mathrm{~s}$, appropriate annealing temperature (Table 1) for $30 \mathrm{~s}, 72^{\circ} \mathrm{C}$ for $30 \mathrm{~s}$.

\subsection{Gene Expression Analysis}

The relative quantification of target genes expression was evaluated using the $\Delta \Delta \mathrm{C}_{\mathrm{T}}$ method. The $\Delta \mathrm{C}_{\mathrm{T}}$ value was determined by $\beta$-actin $\mathrm{C}_{\mathrm{T}}$ value for each sample from the target $\mathrm{C}_{\mathrm{T}}$ value. Fold change in the relative gene expression of target were determined by calculating the $2^{-\Delta \mathrm{CT}}$.

\section{RESULTS}

\subsection{Growth Performance, Carcass Characteristics, Meat Quality}

Body weight, withers height, body length, chest width, hip width of the animals was measured before slaughter. The animal were slaughtered at 12, 18, 24 and 30 mo of age in a commercial slaughterhouse, and the Dressing percentage, pure meat percentage, meat-bone ratio, percentage of high grade cuts, percentage of pure meat were measured. The shear force, fleshcolor, marble score, fat thickness, loin eye area by the special equipment. From Table 2, Table 3 and Table 4, we can found that the Lilu beef cattle have good production and slaughter performance, the performance reach to the criterion of beef cattle.

\subsection{HMGR mRNA Expression in Adipose and Muscle Tissues of Four Different Age Stages}

From Figure 1 and Figure 2, we can see that HMGR mRNA expression level in adipose is higher than in muscle $(\mathrm{P} \leq 0.01)$. In muscle, the $H M G R$ expression increased along with the increase of age, reached to peak in 24 month, then decreased in 30 month. In adipose, the $H M G R$ expression has same trend as in muscle, only the expression reached to peak in 18 month, then decreased.

Table 1. Primer sequences of genes selected for analysis by real-time RT-PCR.

\begin{tabular}{ccccc}
\hline Gene $^{\mathrm{a}}$ & Accession number & Forward primer & Reverse primer & Temp $\left({ }^{\circ} \mathrm{C}\right)$ \\
\hline hmgr & NM_001105613 & AGGAAAGTCTGTGGTCTGTGAAG & CAGGCAATGTAGATGGCAGTTAC & 63 \\
$\beta$-actin & AY141970 & TGACCCAGATCATGTTTGAGA & CAAGGTCCAGACGCAGGAT & 56 \\
\hline
\end{tabular}

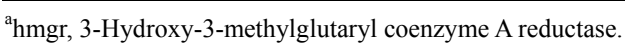

Table 2. The body weight and body size of Lilu beef cattle (means $\pm \mathrm{SE}$ ).

\begin{tabular}{cccccc}
\hline Age & Body weight $/ \mathrm{kg}$ & Withers height/cm & Body length/cm & Chest width/cm & Hip width/cm \\
\hline 12 & $399.58 \pm 23.40 \mathrm{a}$ & $123.63 \pm 3.26$ & $127.42 \pm 5.78$ & $174.75 \pm 3.91$ & $19.58 \pm 0.85$ \\
18 & $496.67 \pm 14.98 \mathrm{~b}$ & $129.50 \pm 1.59$ & $153.83 \pm 3.22$ & $188.83 \pm 2.14$ & $21.93 \pm 0.37$ \\
24 & $570.00 \pm 44.52 \mathrm{c}$ & $131.58 \pm 5.18$ & $158.96 \pm 12.15$ & $197.29 \pm 7.28$ & $22.42 \pm 0.73$ \\
30 & $596.67 \pm 16.47 \mathrm{c}$ & $135.67 \pm 1.23$ & $159.00 \pm 3.92$ & $203.00 \pm 2.74$ & $23.67 \pm 0.21$ \\
\hline
\end{tabular}

Table 3. The slaughter performance of Lilu beef cattle (means \pm SE).

Age (month) Live weight $/ \mathrm{kg}$ Carcass weight $/ \mathrm{kg}$ Dressing percentage/\% Pure meat percentage/cm Meat-bone ratio Percentage of high grade cuts, \%

\begin{tabular}{|c|c|c|c|c|c|c|}
\hline 12 & $395.83 \pm 19.85 \mathrm{a}$ & $228.33 \pm 11.45 \mathrm{a}$ & $57.70 \pm 1.44$ & $48.18 \pm 1.23$ & $5.07 \pm 0.25$ & $7.28 \pm 0.39$ \\
\hline 18 & $486.00 \pm 12.97 b$ & $277.83 \pm 4.87 b$ & $57.27 \pm 1.01$ & $49.10 \pm 0.97$ & $5.03 \pm 0.18$ & $7.24 \pm 0.16$ \\
\hline 24 & $569.17 \pm 17.44 c$ & $323.33 \pm 11.83 c$ & $56.81 \pm 0.92$ & $47.88 \pm 1.34$ & $5.40 \pm 0.57$ & $7.30 \pm 0.46$ \\
\hline 30 & $580.17 \pm 14.48 \mathrm{c}$ & $326.67 \pm 8.53 c$ & $56.32 \pm 0.69$ & $47.72 \pm 0.64$ & $5.59 \pm 0.21$ & $7.96 \pm 0.13$ \\
\hline
\end{tabular}

Note: High grade cuts include beef fillet, boneless beef striploin, rib eye beef, chuck rolls. Ratio is accounted for live weight ratio. 
Table 4. The meat quality of Lilu beef cattle (means $\pm \mathrm{SE}$ ).

\begin{tabular}{cccccccc}
\hline \multirow{2}{*}{ Age (month) } & Shear force/kg.f & \multicolumn{4}{c}{ Fleshcolor } & Fat thickness $/ \mathrm{cm}^{2}$ Loin eye area/cm ${ }^{2}$ \\
\cline { 3 - 6 } & & $\mathrm{L}$ & $\mathrm{a}$ & $\mathrm{b}$ & & \\
\hline 12 & $4.17 \pm 2.53$ & $37.88 \pm 1.73$ & $18.46 \pm 0.99$ & $3.51 \pm 0.36 \mathrm{a}$ & $0.11 \pm 0.02 \mathrm{a}$ & $80.91 \pm 11.92 \mathrm{a}$ \\
18 & $4.28 \pm 0.78$ & $38.30 \pm 1.06$ & $18.42 \pm 0.81$ & $3.69 \pm 0.54 \mathrm{a}$ & $0.21 \pm 0.04 \mathrm{~b}$ & $82.64 \pm 5.65 \mathrm{a}$ \\
24 & $4.20 \pm 2.52$ & $34.66 \pm 2.73$ & $17.60 \pm 1.75$ & $3.71 \pm 1.49 \mathrm{a}$ & $0.23 \pm 0.08 \mathrm{~b}$ & $98.28 \pm 14.13 \mathrm{~b}$ \\
30 & $5.03 \pm 1.18$ & $36.35 \pm 0.98$ & $18.44 \pm 0.67$ & $4.13 \pm 0.54 \mathrm{~b}$ & $0.26 \pm 0.06 \mathrm{~b}$ & $98.96 \pm 4.84 \mathrm{~b}$ \\
\hline
\end{tabular}

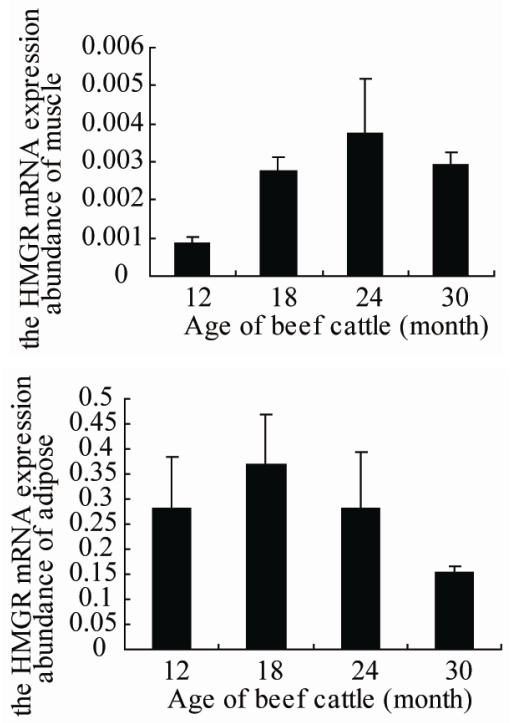

Figure 1. The $H M G R$ expression abundance in muscle and adipose tissues of four age stages of Lilu beef cattle.

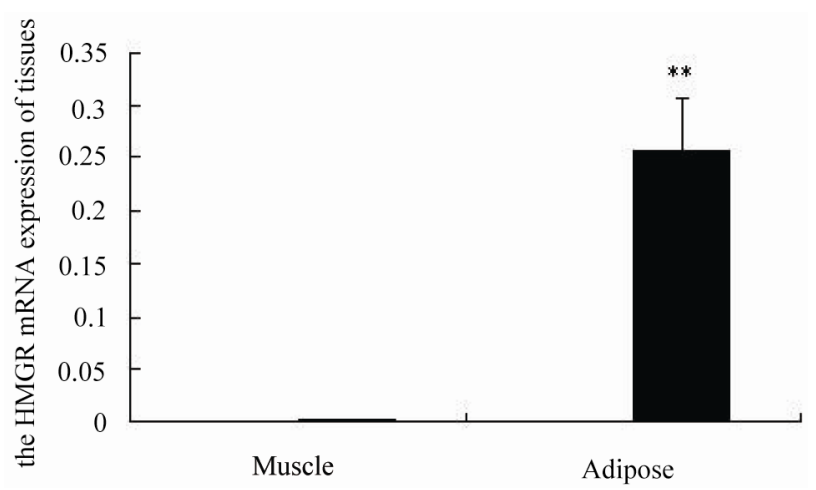

Figure 2. The HMGR expression in muscle and adipose tissues of Lilu beef cattle.

\section{DISCUSSION}

Shandong province has rich local cattle breed resources, Luxi cattle is one of China's four thoroughbred cattle, it has good resistance to disease resistance, strong adaptability, genetic stability, easy sedimentary intramuscular, is the production of high-grade biological characteristics of the ideal varieties. Lilu cattle include blood of Luxi cattle and Limousin, it both also include the good meat quality of Luxi cattle and rapid growth variety of Limousin. Beef is a high quality food of low fat, high protein and low cholesterol. The high-grade beef mast contain rich intramuscular fat to increase the quality and improve level, but lead to cholesterol increases. Development high-grade beef of low cholesterol content what is great significance to improving economic benefit, safeguard human health. To achieve the above goal must first clear cholesterol molecular mechanism of synthesis and control in the body.

The $H M G R$ gene has been widely cloned in many species, i.e. the human $H M G-C o A$ reductase gene has been localized to human chromosome $5 \mathrm{q} 12$ by in situ hybridization and contains 20 exons and 19 introns [6], pig $H M G-C o A$ gene has been localized chromosome $2 \mathrm{q} 21-$ 22 by RH mapping and contains 20 exons and 19 introns [7], chicken [4], rat [8], some plants [3]. Information regarding this gene in cattle, however, is limiting.

Cholesterol content as a biological trait was affected by many factors. Besides the level of $H M G R$ mRNA expression, the cholesterol content was affected by other levels such as the processing and modifying of transcription and translation level [9]. Because this enzyme's role was different in different tissues, so it lead to the cholesterol content was different in different tissues. These factors may affect the amount of cholesterol in tissues. At present, there was not research of $H M G R$ in beef cattle, so a further research of this enzyme would be done. The tissue expression pattern showed that $H M G R$ had strongly expressed differences, which suggested that HMGR might be a constitutively expressing gene. The similar results were reported by Jiang et al. [3]. In addition to, the expression pattern in different tissues suggested that this gene is expressed in a tissue-dependent manner in beef cattle. Our results also show that $H M G R$ expression is different in muscle and adipose tissues. $H M G R$ is the essential enzymes in cholesterol synthesis pathway. Initially, physicians were skeptical of a causal link between cholesterol and CORONARY HEART DISEASE (CHD) because most patients with the disease had plasma cholesterol only slightly higher that the general population 
average (The Lipid Research Clinics Coronary Primary Prevention Trial results [10]. Furthermore, supplementing animal diets with cholesterol can lower hepatic HMGR activity [11]. The efficacy of clinically inhibiting $H M G R$ by various statins and reducing cardiovascular morbidity and mortality has been convincingly demonstrated in primary and secondary prevention trials [12].

Lilu beef cattle has been breeded by several generations in Shandong province, nowadays, it reach to the approved conditions. Our group has done a little work about growth performance, carcass characteristics and meat quality in four age stages of Lilu beef cattle, meanwhile, the $H M G R$ expression of muscle and adipose have been done in four age stages. Further research will be done in order to know the performance and molecular mechanism about HMGR gene in Lilu beef cattle.

\section{ACKNOWLEDGEMENTS}

This study was supported by, the Promotive research fund for excellent young and middle-aged scientists of Shandong Province, Agriculture and biology resources innovation of research, the Thoroughbred Project from Shandong government (2010LZ012), MATS-Beef Cattle System, and National Natural Science Foundation of China (NO. 31100890).

\section{REFERENCES}

[1] Tabas, I. (2002) Cholesterol in health and disease. The Journal of Clinical Investigation, 110, 583-590.

[2] Myant, N.B. (1990) Current approaches to the genetics of coronary heart disease (CHD) including an account of work done at Hammersmith Hospital. Bollettino della Società Italiana di Biologia Sperimentale, 66, 1015-1041.

[3] Jiang, J.H., Kai, G.Y., Cao, X.Y., Chen, F.M., He, D.N. and Liu, Q. (2006) Molecular cloning of a HMG-CoA reductase gene from eucommia ulmoides oliver. Bioscience Reports, 26, 171-181. doi:10.1007/s10540-006-9010-3

[4] Sato, K., Ohuchi, A., Sook, S.H., Toyomizu, M. and Akiba, Y. (2003) Changes in mRNA expression of 3-hy- droxy-3-methylglutaryl coenzyme A reductase and cholesterol 7 alpha-hydroxylase in chickens. Biochimica Biophysica Acta, 1630, 96-102.

[5] Agriculture industrial standard of the People's Republic (NY/T1180-2006). The measuring method of muscle tender and shear force. Ministry of Agriculture of the People's Republic.

[6] Humphries, S.E., Tata, F., Henry, I., Barichard, F., Holm, M., Junien, C. and Williamson, R. (1985) The isolation, characterization, and chromosomal assignment of the gene for human hydroxyl 3-methylglutaryl coenzyme A reductase (HMG-CoA reductase). Human Genetics, 71, 254-258. doi:10.1007/BF00284585

[7] Wang, X.F. (2006) Molecular cloning, expression analysis, chromosome mapping and polymorphism analysis of porcine HMGR gene. PhD Thsis, China Agricultural University.

[8] Sundaresan, S., Yang-Feng, T.L. and Francke, U. (1989) Genes for HMG-CoA reductase and serotonin 1a receptor are on mouse chromosome 13. Somatic Cell and Molecular Genetics, 15, 465-469. doi:10.1007/BF01534897

[9] Goldwasser, J., Cohen, P.Y., Yang, E., Balaguer, P., Yarmush, M.L. and Nahmias, Y. (2010) Transcriptional regulation of human and rat hepatic lipid metabolism by the grapefruit flavonoid naringenin: Role of PPAR $\alpha$, PPAR $\gamma$, and LXR $\alpha$. PLoS One, 5, e12399. doi:10.1371/journal.pone.0012399

[10] Tobert, J.A. (2003) Lovastatin and beyond: The history of the HMG-CoA reductase inhibitors. Nature Reviews Drug Discovery, 2, 517-526. doi:10.1038/nrd1112

[11] Ness, G.C. (2003) Physiological and pharmacological regulation of hepatic 3-hydroxy-3-methylglutaryl coenzyme A reductase. Current Medicinal Chemistry-Imunology, Endocrine \& Metabolic Agents, 3, 219-227. doi:10.2174/1568013033483366

[12] Rasmusseen, L.M., Hanzen, P.R., Nabipour, M.T., Olesen, P., Kristiansen, M.T. and Ledet, T. (2001) Diverse effects of inhibition of 3-hydroxy-3-methylglutaryl-CoA reductase on the expression of VCAM-1 and E-selectin in endothelial cells. The Biochemical Journal, 360, 363-370. doi:10.1042/0264-6021:3600363 